\title{
Plant persistence traits in fire-prone ecosystems of the Mediterranean basin: a phylogenetic approach
}

\author{
J. G. Pausas and M. Verdú
}

Pausas, J. G. and Verdú, M. 2005. Plant persistence traits in fire-prone ecosystems of the Mediterranean basin: a phylogenetic approach. - Oikos 109: 196-202.

\begin{abstract}
The two main fire response traits found in the Mediterranean basin are the resprouting capacity $(\mathrm{R})$ and the propagule-persistence capacity $(\mathrm{P})$. Previous studies suggested that these two traits might be correlated. In this paper we first test whether $\mathrm{R}$ and $\mathrm{P}$ have evolved independently. Then, we ask if the correlation occurs because (a) one trait is not the target of selection but it is genetically linked to the other trait which is the one under selection pressure (indirect selection), or (b) because different evolutionary responses to the same selective pressure are acting in parallel on populations at different genetic starting points (parallel selection). Finally, we test to what extent resprouting is associated with some vegetative and reproductive traits.

To answer these questions we used a traits database for the eastern Iberian Peninsula and we assembled the phylogenetic tree on the basis of published information. The results indicate that the two traits are negatively associated and support the parallel selection scenario in which changes in $\mathrm{R}$ precedes changes in $\mathrm{P}$. The phylogenetic-informed associations of resprouting with other traits (plant height, age at maturity) support the existence of allocation tradeoffs.

The results are consistent with the biogeographical history of the Mediterranean basin flora where most of lineages already resprouted to persist after a disturbance during the Tertiary, thus making it improbable that an additional costly persistence strategy would evolve under the Quaternary climatic conditions.
\end{abstract}

J. G. Pausas, Centro de Estudios Ambientales del Mediterráneo (CEAM), C/ Charles R. Darwin 14, Parc Tecnològic, ES-46980 Paterna, València, Spain (juli@ceam.es). - M. Verdú,, Centro de Investigaciones sobre Desertificación (CIDE, CSIC-UV), Cami de la Marjal s/n Apartado Oficial, ES-46470 Albal, València, Spain.

Species persistence in a fire-prone environment depends on the persistence capacity at individual and at population level (Pausas et al. 2004). In the Mediterranean basin, and under crown fire (stand-replacing) regimes, individuals may persist thanks to the resprouting capacity. In this environment populations may persist even if the individuals do not resprout, if their propagules survive fires. Thus, two main fire response plant traits can be recognised in the Mediterranean basin, the resprouting capacity $(\mathrm{R})$ and the propagule-persistence capacity $(\mathrm{P})$. Different resprouting sources (lignotuber, epicormic buds, rhizomes, roots, etc; Pausas 1997, Bellingham and Sparrow 2000, Bond and Midgley
2001) and propagule-persistence mechanisms (hardcoated seeds, serotiny; Trabaud and Oustric 1989, Keeley 1991, Lamont et al. 1991, Roy and Sonié 1992, Thanos and Rundel 1995) can provide a diverse genetic context or starting points on which the selection may act. Both traits have been widely studied in different environments; however, no study has compared these two strategies using a phylogenetic perspective.

Previous nonphylogenetically informed studies suggested that R and P may be correlated, and that the type of association may depend on the biogeographical history of the area (Pausas 2001, Pausas et al. 2004). Thus even though four combinations are possible 
$(\mathrm{R}+\mathrm{P}+, \mathrm{R}+\mathrm{P}-, \mathrm{R}-\mathrm{P}+$ and $\mathrm{R}-\mathrm{P}-)$, some of them should be more frequent (Pausas 1999). Specifically, for the Mediterranean basin it has been proposed that these two traits may be negatively associated in such a way that most plants with resprouting capacity $(\mathrm{R}+)$ would not have traits for propagule persistence $(\mathrm{P}-)$ and, viceversa, that most species with propagule-persistence capacity $(\mathrm{P}+)$ would not have the capacity to resprout $(\mathrm{R}-)$. These two are often called obligate resprouters $(\mathrm{R}+\mathrm{P}-)$ and obligate seeders $(\mathrm{R}-\mathrm{P}+)$ to emphasise their sole mode of postfire regeneration. To what extent this association is produced by phylogenetic relatedness remains untested.

The phylogenetic association between $\mathrm{R}$ and $\mathrm{P}$ may arise from different scenarios (based on Armbruster 2002):

1) Indirect selection: one trait ( $\mathrm{R}$ or $\mathrm{P}$ ) is not the target of selection but it is genetically linked to the other trait which is the one under selection pressure. In this case, changes in $\mathrm{R}$ and $\mathrm{P}$ should occur simultaneously on the phylogeny.

2) Parallel selection: both traits are the target of selection and appear nonsimultaneously through different evolutionary responses to the same selective pressure (i.e. disturbance type/regime) acting in parallel on populations at different starting points. In this case we would expect that one of the traits would appear on the same phylogenetic branch as the other, but later. Within this scenario, the negative association between $\mathrm{R}$ and $\mathrm{P}$ can appear from the result of an allocation tradeoff.

Two important tradeoffs may be considered in the R-P association, a vegetative tradeoff and a reproductive tradeoff. The vegetative tradeoff predicts that resprouters should allocate more on belowground growth, while nonresprouters should allocate more on aboveground growth, and therefore, it has been postulated that resprouters should be shorter (Midgley 1996, Kruger et al. 1997). For plant persistence, nonresprouters should invest in numerous offspring and, consequently, the reproductive tradeoff suggests that they should allocate less resources per propagule unit (Smith and Fretwell 1974, Harper 1977, Keeley and Zedler 1977, Leishman 2001, Lamont and Wiens 2003). As a result, nonresprouters should tend to have small seeds and less costly (dry) fruits in contrast to resprouters that should have the opposite trends. Also, nonresprouters may increase offspring quantity by reducing generation time, that is, by maturing earlier (Wells 1969, Verdú 2002, Lamont and Wiens 2003).

Correlational selection or selective covariance (Herrera 2001) could also explain the association of traits if both appear simultaneously as a response to the same selective pressure. Although we cannot discard this scenario (see Armbruster 2002 for a detailed discussion), we would expect that correlational selection would lead to $\mathrm{R}+\mathrm{P}+$ being a frequent combination, and this is not observed in the Mediterranean basin.

In this paper we first test the negative phylogenetic association between $\mathrm{R}$ and $\mathrm{P}$ in our study area; second, we test whether the association between $\mathrm{R}$ and $\mathrm{P}$ arises from the indirect or the parallel selection scenario defined above; and third, we test to what extent resprouting is associated with some vegetative and reproductive traits both before and after considering the phylogenetic relatedness among species. To answer these questions we used a trait database for the eastern Iberian Peninsula and we assembled a supertree on the basis of published phylogenies. Then we tested the correlated evolution by using a likelihood approach; and finally, following the hierarchical framework of Pausas et al. (2004), we related R to other plant traits by incorporating the phylogenetic relatedness among species.

\section{Material and methods}

\section{Data}

The data was obtained from the EIBER data set (Pausas et al. 2004) which contains trait data for plants growing in the eastern Iberian Peninsula. From this dataset, we extracted 37 common woody species growing in fireprone (lowland) communities and in which enough information was available. Parameters obtained from the dataset were, the postfire response traits (sensu Pausas et al. 2004): resprouting capacity (R), and postfire propagule-persistence capacity $(\mathrm{P})$; then, we also extracted other traits not directly related to fire such as several reproductive characters (seed mass, fruit mass, age at maturity and fruit type) and a vegetative character (plant height). Resprouting ability was considered a binary character with levels codified as $\mathrm{R}+$ (presence; species in which individuals are able to resprout after 100\% scorch by fire) and $\mathrm{R}$ - (absence). Similarly, propagule persistence $(\mathrm{P})$ was codified as a binary character with $\mathrm{P}+$ (species in which the population locally persists in propagule form, i.e. seed or fruit after $100 \%$ scorch by fire) and $\mathrm{P}-$. Maximum plant height were obtained from local floras, fruit and seed mass from a local Seed Bank (Banc de Llavors, Generalitat Valenciana), and maturity age from sparse references and field observations.

A phylogenetic tree was assembled for this data set by pruning the Soltis et al. (2000) tree to the family level and subsequently grafting the species of the Mediterranean basin (Fig. 1). Phylogenetic information under the family level was obtained from Doyle et al. (1997) (Fabaceae), Manos et al. (1999) (Quercus), and Wallander and Albert (2000) (Oleaceae). Thus, we 


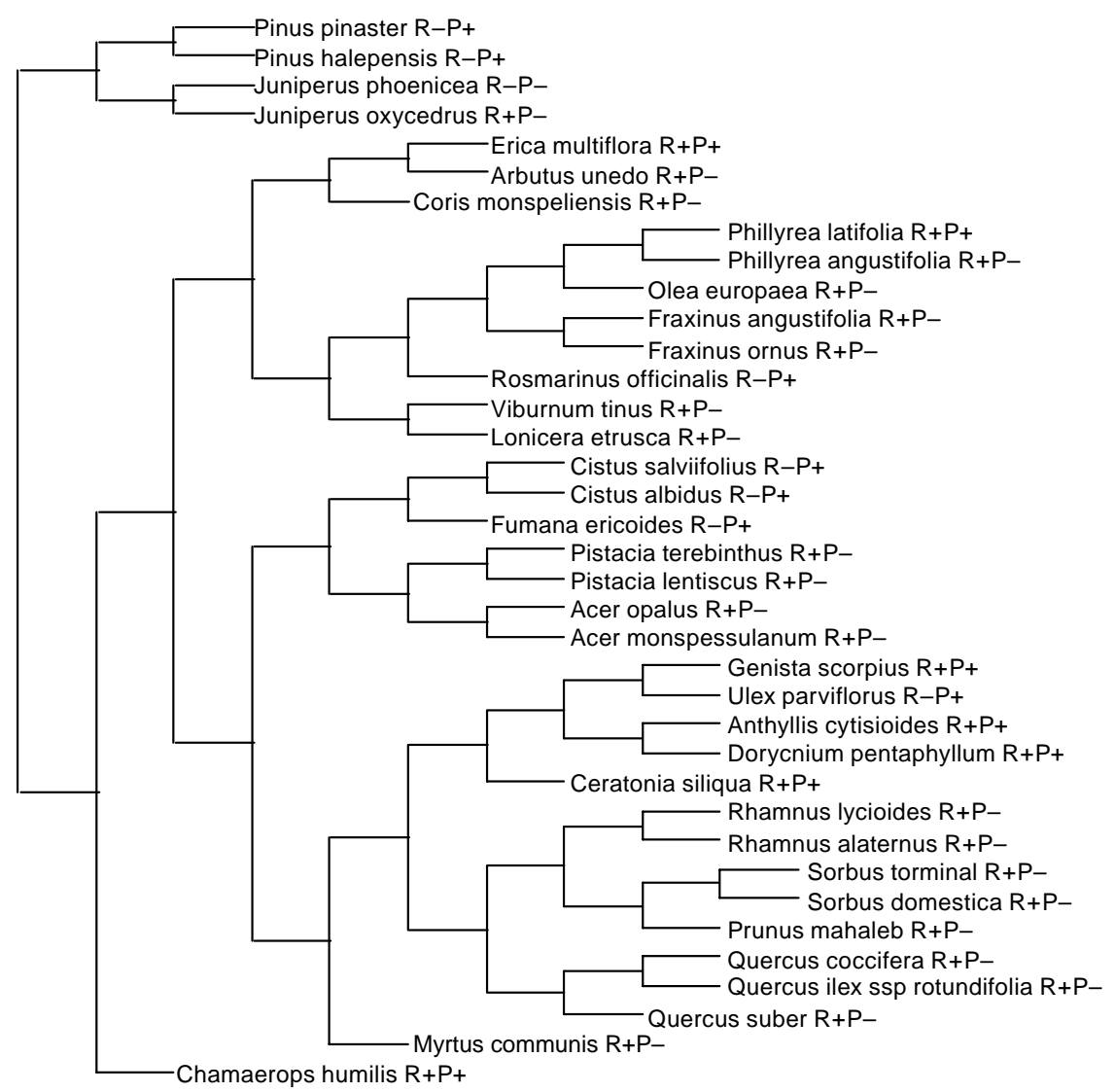

Fig. 1. Phylogenetic tree for the EIBER data set showing the trait states for $\mathrm{R}$ and $\mathrm{P}$. Nomenclature following Bolòs et al. (1990).

obtained a fully resolved phylogenetic tree in which unit branch lengths were assumed. As in all phylogenetically informed comparative studies, conclusions depend on the underlying phylogenies, and therefore the results are subject to phylogenetic uncertainties (Donoghue and Ackerly 1996, Huelsenbeck et al. 2000).

\section{Statistical analysis}

Correlated evolution between $\mathrm{R}$ and $\mathrm{P}$ on the phylogenetic tree was studied with the help of the Discrete software that implements a continuous-time Markov model in a maximum likelihood framework (Pagel 1994). The correlated evolution is tested by comparing the likelihood of a model in which $\mathrm{R}$ and $\mathrm{P}$ are allowed to evolve independently against another model in which $\mathrm{R}$ and $\mathrm{P}$ evolve in a dependent fashion. The significance of the likelihood ratio test (LR) comparing both models was estimated by running 1000 Monte Carlo simulations. We repeated the analysis several times to ensure reaching the global, and not local, optimum of the maximum likelihood surface (Pagel 1994).

The two alternative scenarios for correlated evolution proposed by Armbruster (2002) were tested in the Discrete software by restricting the parameters in the dependent model and then comparing the likelihoods of the independent and the dependent models. The parameters $\left(q^{\prime} s\right)$ indicate the transition rates between characterstate combinations (Fig. 2) and are derived on the basis of a maximum likelihood approach (Pagel 1994). The indirect selection scenario predicts a simultaneous evolutionary change in both $\mathrm{R}$ and $\mathrm{P}$, and it is tested by means of a temporal-order test in which q24+q34 》 $\mathrm{q} 12+\mathrm{q} 13$ (Armbruster 2002). The parallel scenario predicts both a temporal order in the evolutionary change and a contingent evolution in which the state of the first trait appearing in the temporal order affects the probability of evolutionary change in the states of the second trait. Thus, if $\mathrm{R}$ has influenced the evolution of $\mathrm{P}$, then the temporal order test predicts that $\mathrm{R}$ changes precede $P$ changes $(q 13>q 12)$ and the subsequent contingent-change test predicts that the state of $R$ $(\mathrm{R}+$ or $\mathrm{R}-)$ affects the probability of change in $\mathrm{P}$ (q34>q12). Alternatively, if $P$ has influenced the evolution of $\mathrm{R}$, then the temporal order test $(\mathrm{q} 12>\mathrm{q} 13)$ and the contingent-change test $(\mathrm{q} 24>\mathrm{q} 13)$ predict the reverse situation.

Phylogenetic associations of $\mathrm{R}$ with characters linked to the reproductive (fruit type, seed and fruit weight, age at maturity) and vegetative (plant height) tradeoffs were analyzed by means of a generalized estimating equation 
(GEE) procedure that uses a GLM approach incorporating the phylogenetic relatedness among species as a correlation matrix in the model. The advantage of using GEE in relation to other comparative methods is that the response variable can follow non-normal distributions, the independent variables could be continuous or categorical and the model can include additive, interactive and nested effects among the predictors (Paradis and Claude 2002 for a detailed description and evaluation of the method). GEE is more general than most comparative methods but currently it can only be applied to the Brownian motion evolutionary scenario (Felsenstein 2004). Gaussian distribution of errors was considered after log-transformation of seed and fruit weight, age at maturity, leaf size and plant height whereas binomial distribution was considered in the model to test for fruit type (dry vs fleshy) differences between $\mathrm{R}+$ and $\mathrm{R}-$. The GEE analyses were run using the APE package (Paradis and Claude 2002, Paradis et al. 2004).

\section{Results}

\section{Correlated evolution between resprouting $(R)$ and propagule persistance $(\mathrm{P})$}

There was a significant negative association between the two binary traits, indicating that $\mathrm{R}+\mathrm{P}-$ and $\mathrm{R}-\mathrm{P}+$ were more frequent than could be expected by chance $\left(\chi^{2}=10.70,9 \mathrm{df}=1, \mathrm{p}=0.002\right)$. Incorporating the phylogenetic relatedness of the species (Fig. 1) in the analysis, the association remained significant (likelihood ratio $=4.82 ; \mathrm{p}=0.014$, number of simulations $=1000$ ), and suggested that there was a correlated evolution of traits (Fig. 2).

The correlated evolution between $\mathrm{R}$ and $\mathrm{P}$ did not seem to have appeared simultaneously in the phylogeny, as the indirect selection scenario predicts (Table 1). In contrast, the temporal order in which $\mathrm{R}$ changes precede $\mathrm{P}$ changes was the most likely sequence. Furthermore, a

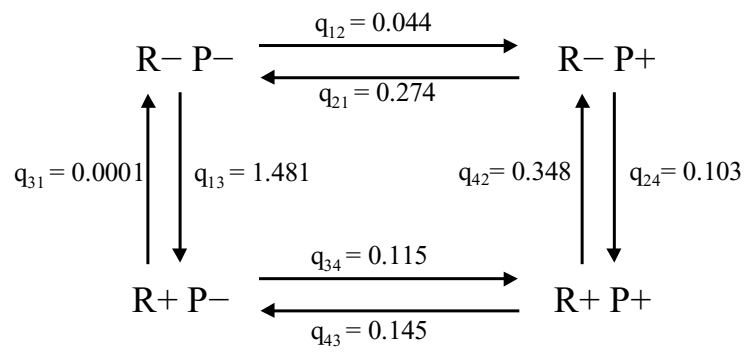

Fig. 2. Flow diagram with the forward and backward transition rate parameters (qij) between the two character-state combinations as defined in Page (1994). Rate parameters indicate the rate at which one trait $(\mathrm{R}$ or $\mathrm{P}$ ) changes from - to + (or vice versa) when the other trait is fixed. contingent-change occurs as long as the rate at which $\mathrm{P}$ changes from $\mathrm{P}-$ to $\mathrm{P}+$ depends upon the state of $\mathrm{R}$. These results support the parallel selection scenario in which $\mathrm{R}$ has influenced the evolution of $\mathrm{P}$ (Table 1).

\section{Traits associated with $\mathbf{R}$}

In four of the five traits studied, the differences between $\mathrm{R}+$ and $\mathrm{R}$ - were not significant (non-phy analysis in Table 2). As a result of incorporating phylogenetic relatedness, the significance changes in different directions (phy analysis in Table 2).

In the vegetative trait studied (plant height), the differences between $\mathrm{R}+$ and $\mathrm{R}-$ were marginally significant when considering the phylogenetic relatedness across species (Table 2); resprouters were taller than nonresprouters. Including life form (tree/shrub) as a factor in the model did not change the results: $\mathrm{R}$ and life form were marginally significant ( $p=0.08$ and $p=0.09$, respectively), and the interaction was not significant.

Age at maturity was not significant in the nonphylogenetic test, but it became clearly significant when phylogenetic relatedness was considered, indicating that $\mathrm{R}+$ mature later than $\mathrm{R}-$. In contrast, both seed and fruit mass remained nonsignificant even after phylogeny was taken into account. (Table 2).

Only one from the eight $\mathrm{R}$ - species had fleshy fruits whereas for the $\mathrm{R}+$ this proportion was 17 from 29 , and so, the non-phylogenetic analysis detected significant differences. However, differences vanished when phylogeny was considered (Table 2).

\section{Discussion}

Resprouting capacity $(\mathrm{R})$ and propagule persistence $(\mathrm{P})$ showed a negative evolutionary correlation in woody plants of the Mediterranean basin. Schwilk and Ackerly (2001) also found a similar evolutionary correlation between bark thickness (which, as resprouting, it allows individual persistence; Pausas and Lavorel 2003) and serotiny (a propagule persistence trait) in Pinus species. The association between $\mathrm{R}$ and $\mathrm{P}$ can be the result of forces other than adaptation. For example, such relationships might occur because the trait is evolutionarily linked to a second trait (the true adaptation) that is being selected on by the environment (Martins 2000). The fact that $\mathrm{R}$ and $\mathrm{P}$ did not appear simultaneously on the phylogeny discard this scenario. That is, the correlated evolution does not come from an indirect selection in which both traits are genetically linked with only one being under selection pressure (disturbance such as fire).

In contrast, our results support the idea that $\mathrm{R}$ and $\mathrm{P}$ did not appear simultaneously but rather that $\mathrm{R}$ preceded $\mathrm{P}$ and the state of $\mathrm{R}$ affected the probability 
Table 1. Results of the temporal order and contingent-change tests for the two different evolutionary scenarios. Shown are the conditions for the test (based on the relative magnitude of the q parameters, see Fig. 2), the values of these parameters in our data, and the LR test (when the parameters meet the conditions, otherwise it is indicated by NA). The final column shows whether the scenario is supported on the basis of the two tests.

\begin{tabular}{lllr}
\hline Evolutionary scenario & Temporal order test & Contingent-change test & Supported scenario? \\
\hline Indirect selection & $\mathrm{q} 24+\mathrm{q} 34>\mathrm{q} 12+\mathrm{q} 13$ & - & no \\
& $0.218<1.525$ & & \\
NA & & & \\
Parallel selection & $\mathrm{q} 13>\mathrm{q} 12$ & $\mathrm{q} 34>\mathrm{q} 12$ & yes \\
$-\mathrm{R}$ precedes P & $1.48>0.044$ & $0.115>0.044$ & no \\
& $\mathrm{LR}=4.75 ; \mathrm{p}=0.01$ & $\mathrm{LR}=4.94 ; \mathrm{p}=0.005$ & \\
$-\mathrm{P}$ precedes R & $\mathrm{q} 12>\mathrm{q} 13$ & $0.103<1.481$ & $\mathrm{q} 13$ \\
& $0.044<1.48$ & $\mathrm{NA}$ &
\end{tabular}

of change in $\mathrm{P}$. Thus, species able to resprout almost never evolved persistent propagules while species unable to resprout had a great probability of evolving persistent propagules. This is consistent with the parallel selection scenario in which the negative association between traits can appear as a product of allocation tradeoffs. Alternatively, genetic linkage between the two traits (pleiotropy) could theoretically explain this scenario (Armbruster 2002), but given the wide variety of physiological basis for both traits this possibility seems unlikely. Furthermore, there is a bulk of information on the allocation tradeoffs between resprouters and nonresprouters (Keeley and Keeley 1977, Keeley 1991, Hansen et al. 1991, Bell and Ojeda 1999, Lamont and Wiens 2003).

In the Mediterranean basin, the negative association between $\mathrm{R}$ and $\mathrm{P}$ reduces the four functional groups $(\mathrm{R}+\mathrm{P}+, \mathrm{R}+\mathrm{P}-, \mathrm{R}-\mathrm{P}+$ and $\mathrm{R}-\mathrm{P}-$; Pausas 1999, Pausas et al. 2004) to two dominant groups in which the trade-offs have been typically studied: the resprouters $(\mathrm{R}+\mathrm{P}-)$ and the non-resprouters, also called seeders $(\mathrm{R}-\mathrm{P}+)$.

If resprouters tend to allocate resources to belowground resources (Bell and Ojeda 1999, Schwilk 2002), then juveniles of resprouters should grow slower than juveniles of nonresprouters which lack resprouting structures (Chapin et al. 1990, Iwasa and Kubo 1997). This relation has been supported in species from the
Mediterranean basin (Verdú 2002) and Australia (Pate et al. 1990, Hansen et al. 1991, Yates et al. 2003, Pausas et al. 2004), although an extensive phylogenetically controlled analysis remains to be done. In this context we should expect non-resprouters to be taller (Midgley 1996, Pausas et al. 2004); however, our results indicate an opposite trend. Higher growth rates in nonresprouters may be counterbalanced by a greater longevity in resprouters (i.e. longevity may mask the tradeoff). Unfortunately, longevity data are anecdotal; however, lifespan is positively correlated with age at maturity (Gould 1977, Verdú 2002). Our results show a significant difference in age at maturity (i.e. resprouters mature later) when phylogenetic relatedness is considered. Later maturity for resprouters than for nonresprouters has been shown, especially when considering a single taxonomic group (Epacridaceae in Bell and Pate 1996; Proteaceae in Pausas et al. 2004).

The reproductive allocation tradeoff was evident for age at maturity but not for seed and fruit characters. As predicted, nonresprouters tended to mature earlier, which has been linked to high fecundity, short life spans, limited parental care and rapid development (Gould 1977, Verdú 2002). All these characteristics properly match the nonresprouting strategy. Mean values for seed and fruit mass were quite different (larger for resprouters), but the variability was so high that no significant differences were found. Concerning fruit type, our data

Table 2. Mean and standard deviation of different traits for non-resprouting $(\mathrm{R}-)$ and resprouting $(\mathrm{R}+)$ species, and the p-value for the nonphylogenetic (ANOVA for quantitative and chi-square for qualitative traits) and the phylogenetic analyses (generalised estimation equation). All quantitative data are log-transformed previous to the analysis. P-value of the chi-square was based on 2000 Monte Carlo simulations. P values are shown when $<0.1$ (ns otherwise).

\begin{tabular}{|c|c|c|c|c|c|c|}
\hline \multirow[t]{2}{*}{ Traits } & \multicolumn{2}{|c|}{$\mathrm{R}-$} & \multicolumn{2}{|c|}{$\mathrm{R}+$} & \multirow{2}{*}{$\frac{\text { Non-phy }}{\mathrm{p}}$} & \multirow{2}{*}{$\begin{array}{c}\text { Phy } \\
\text { P }\end{array}$} \\
\hline & Mean & $\mathrm{SD}$ & Mean & SD & & \\
\hline Plant height (m) & 7.95 & 11.12 & 8.47 & 7.77 & ns & 0.051 \\
\hline Seed mass (mg) & 14.77 & 20.61 & 434.80 & 1117.91 & ns & ns \\
\hline Fruit mass (mg) & 329.73 & 464.39 & 995.62 & 1736.96 & ns & ns \\
\hline Age at maturity (yr) & 6.0 & 4.33 & 10.0 & 4.00 & ns & 0.008 \\
\hline Fruit type (dry/fleshy) & - & - & - & - & 0.035 & $\mathrm{~ns}$ \\
\hline
\end{tabular}


significantly support the tendency of resprouters to have fleshy fruits and of nonresprouters to have dry (less costly) fruits when phylogeny is not considered. A similar tendency has been observed for Californian species (Pausas et al. 2004), but not for Australian species (French and Westoby 1996, Pausas et al. 2004). By including phylogenetic relatedness in our analysis, the relation vanished, emphasising the obviously strong relation between fruit type and phylogeny. Similarly, in Australia the type of fruit was also much more related to taxonomic group than to R (Pausas et al. 2004).

Although some other characters should be considered to unambiguously test tradeoffs (e.g. seed production, lifespan, root:shoot ratio), our phylogeneticallyinformed analysis supports the existence of an allocation tradeoff that could explain the negative association between $\mathrm{R}$ and $\mathrm{P}$ under the parallel selection scenario. Under this scenario, lineages already resprouting to persist after a disturbance (i.e. hurricanes, herbivory) from different starting points (lignotubers, rhizomes, adventitious buds, etc) would be less likely to evolve another additional strategy, like seeding. On the other hand, the fact that $\mathrm{R}$ precede changes in $\mathrm{P}$, as expected under this scenario, is consistent with both the ancestral origin of resprouting (Wells 1969) and the evolutionary history of the Mediterranean basin, where resprouters correspond to older lineages (Tertiary with tropical conditions) and non-resprouters to younger lineages (Quaternary with Mediterranean conditions; Herrera 1992, Lloret et al. 1999, Verdú 2000, Verdú et al. 2002, 2003).

Acknowledgements - This work has been partially financed by the European project EUFireLab (EVR1-CT-2002-40028) and by the Spanish project SINREG (REN2003-07198-C02-02/ GLO). We thank P. García-Fayos, F. Ojeda and D. Ackerly for helpful comments on the manuscript. CEAM is supported by Generalitat Valenciana and Bancaixa.

\section{References}

Armbruster, W. S. 2002. Can indirect selection and genetic context contribute to trait diversification? A transitionprobability study of blossom-colour evolution in two genera. - J. Evol. Biol. 15: 468-486.

Bellingham, P. J. and Sparrow, A. D. 2000. Resprouting as a life history strategy in woody plant communities. - Oikos 89: 409-416.

Bell, T. L. and Pate, J. S. 1996. Growth and fire response of selected Epacridaceae of south-western Australia. - Austr. J. Bot. 44: 509-526.

Bell, T. L. and Ojeda, F. 1999. Underground starch storage in Erica species of the Cape Floristic Region-differences between seeders and resprouters. - New Phytol. 144: $143-152$.

Bolòs, O., Vigo, J., Masalles, R. M. et al. 1990. Flora manual dels Països Catalans. - Ed. Pòrtic.

Bond, W. J. and Midgley, J. J. 2001. Ecology of sprouting in woody plants: the persistence niche. - Trends Ecol. Evol. 16: $45-51$.
Chapin, F. S., Schulze, E. D. and Mooney, H. A 1990. The ecology and economics of storage in plants. - Annu. Rev. Ecol. Syst. 21: 423-447.

Donoghue, M. J. and Ackerly, D. D. 1996. Phylogenetic uncertainities and sensitivity analysis in comparative biology. - Philos. Trans. R. Soc. Lond. Ser. B-Biol Sci. 351: 1241-1249.

Doyle, J. J., Doyle, J. L., Ballenger, J. A. et al. 1997. A phylogeny of the chloroplast gene RBCL in the Leguminosae: taxonomic correlations and insights into the evolution of nodulation. - Am. J. Bot. 84: 541-544.

Felsenstein, J. 2004. Inferring phylogenies. - Sinauer Associates Inc.

French, K. and Westoby, M. 1996. Vertebrate-dispersed species in a fire-prone environment. - Austr. J. Ecol. 21: 379-385.

Gould, S. J. 1977. Ontogeny and phylogeny. - The Belknap Press of Harvard Univ. Press.

Hansen, A., Pate, J. S. and Hansen, A. P. 1991. Growth and reproductive performance of a seeder and a resprouter species of Bossiaea as a function of plant age after fire. - Ann. Bot. 67: 497-509.

Harper, J. L. 1977. Population biology of plants. - Academic Press.

Herrera, C. M. 1992. Historical effects and sorting processes as explanations for contemporary ecological patterns: character syndromes in Mediterranean woody plants. - Am. Nat. 140: $421-446$.

Herrera, C. M. 2001. Deconstructing a floral phenotype: do pollinators select for corolla integration in Lavandula latifolia? - J. Evol. Biol. 14: 574-584.

Huelsenbeck, J. P., Rannala, B. and Masly, J. P. 2000. Accommodating phylogenetic uncertainty in evolutionary studies. - Science 288: 2349-2350.

Iwasa, Y. and Kubo, T. 1997. Optimal size of storage for recovery after unpredictable disturbance. - Evol. Ecol. 11: $41-65$.

Keeley, J. E. 1991. Seed germination and life history syndromes in the Californian chaparral. - Bot. Rev. 57: 81-116.

Keeley, J. E. and Keeley, S. C. 1977. Energy allocation patterns of a sprouting and a nonsprouting species of Arctostaphylos in the California chaparral. - Am. Midl. Nat. 98: 1-10.

Keeley, J. E. and Zedler, P. H. 1978. Reproduction of chaparral shrubs after fire: a comparison of sprouting and seedling strategies. - Am. Midl. Nat. 99: 142-161.

Kruger, L. M., Midgley, J. J. and Cowling, R. M. 1997. Resprouters vs reseeders in South African forest trees-a model based on forest canopy height. - Funct. Ecol. 11: $101-105$.

Lamont, B. B. and Wiens, D. 2003. Are seed set and speciation rates always low among species that resprout after fire, and why? - Evol. Ecol. 17: 277-292.

Lamont, B. B., Le Maitre, D. C., Cowling, R. M. et al. 1991. Canopy seed storage in woody plants. - Bot. Rev. 57: 277-317.

Leishman, M. R. 2001. Does the seed size/number trade-off model determine plant community structure? An assessment of the model mechanisms and their generality. - Oikos 93: 294-302.

Lloret, F., Verdú, M., Flores-Hernández, N. et al. 1999. Fire and resprouting in Mediterranean ecosystems; insights from an external biogeographical region, the Mexical shrubland. - Am. J. Bot. 86: 1655-1661.

Manos, P. S., Doyle, J. J. and Nixon, K. C. 1999. Phylogeny, biogeography, and processes of molecular differentiation in Quercus subgenus Quercus (Fagaceae). - Mol. Phylogen. Evol. 12: 333-349.

Martins, E. P. 2000. Adaptation and the comparative method. - Trends Ecol. Evol. 15: 295-299.

Midgley, J. J. 1996. Why the world's vegetation is not totally dominated by resprouting plants; because resprouters are shorter than seeders. - Ecography 19: 92-95. 
Pagel, M. 1994. Detecting correlated evolution on phylogenies: a general method for the comparative analysis of discrete characters. - Proc. R. Soc. (B) 255: 37-45.

Paradis, E. and Claude, J. 2002. Analysis of comparative data using generalized estimating equations. - J. Theor. Biol. 218 : $175-185$.

Paradis, E., Claude, J. and Strimmer, K. 2004. APE: analyses of phylogenetics and evolution in R langauge. - Bionformatics 20: $289-290$.

Pate, J. S., Froend, R. H., Bowen, B. J. et al. 1990. Seedling growth and storage characteristics of seeder and resprouter species of Mediterranean-type ecosystems of SW Australia. - Ann. Bot. 65: 585-601.

Pausas, J. G. 1997. Resprouting of Quercus suber in NE Spain after fire. - J. Veg. Sci. 8: 703-706.

Pausas, J. G. 1999. Mediterranean vegetation dynamics: modelling problems and functional types. - Plant Ecol. 140: $27-39$.

Pausas, J. G. 2001. Resprouting vs seeding, a Mediterranean perspective. - Oikos 94: 193.

Pausas, J. G. and Lavorel, S. 2003. A hierarchical deductive approach for functional types in disturbed ecosystems. - J. Veg. Sci. 14: 409-416.

Pausas, J. G., Bradstock, R. A., Keith, D. A., Fire Network., GCTE et al. 2004. Plant functional traits in relation to fire in crown-fire ecosystems. - Ecology 85: 1085-1100.

Roy, J. and Sonié, L. 1992. Germination and population dynamics of Cistus species in relation to fire. - J. Appl. Ecol. 29: 64-655.

Schwilk, D. W. 2002. Plant evolution in fire-prone environments. Ph.D. thesis. - Stanford Univ.

Schwilk, D. W. and Ackerly, D. D. 2001. Flammability and serotiny as strategies: correlated evolution in pines. - Oikos 94: $326-336$.
Smith, C. C. and Fretwell, S. D. 1974. The optimal balance between size and number of offsprings. - Am. Nat. 108: 499-506.

Soltis, D. E, P. S., Soltis, M. W., Chase, M. E. et al. 2000. Angiosperm phylogeny inferred from $18 \mathrm{~S}$ rDNA, rbcL, and atpB sequences. - Bot. J. Linn. Soc. 133: 381-461.

Thanos, C. A. and Rundel, P. W. 1995. Fire-followers in chaparral: nitrogenous compounds trigger seed germination. - J. Ecol. 83: 207-216.

Trabaud, L. and Oustric, J. 1989. Heat requirements for seed germination of three Cistus species in the garrigue of southern France. - Flora 183: 321-325.

Verdú, M. 2000. Ecological and evolutionary differences between Mediterranean seeders and resprouters. - J. Veg. Sci. 11: 265-268.

Verdú, M. 2002. Age at maturity and diversification in woody angiosperms. - Evolution 56: 1352-1361.

Verdú, M., Barrón-Sevilla, J. A., Valiente-Banuet, A. et al. 2002. Mexical plant phenology: is it similar to Mediterranean communities? - Bot. J. Linn. Soc. 138: 297-303.

Verdú, M., Dávila, P., García-Fayos, P. et al. 2003. "Convergent" traits of Mediterranean woody plants belong to pre-Mediterranean lineages. - Biol. J. Linn. Soc. 78: 1-16.

Wallander, E. and Albert, V. A. 2000. Phylogeny and classification of Oleaceae based on RPS16 and TRNL-F sequence data. - Am. J. Bot. 87: 1827-1841.

Wells, P. V. 1969. The relation between mode of reproduction and extent of specialisation in woody genera of the California chaparral. - Evolution 23: 264-267.

Yates, C. J., Hopper, S. D., Brown, A. et al. 2003. Impact of two wildfires on endemic granite outcrop vegetation in western Australia. - J. Veg. Sci. 14: 185-194. 